\section{Autism: functional brain mapping of exceptional calendar capacity}

\author{
NATHALIE BODDAERT, CATHERINE BARTHÉLÉMY, JEAN-BAPTISTE POLINE, \\ YVES SAMSON, FRANCIS BRUNELLE and MÔNICA ZILBOVICIUS
}

\author{
Background 'Autistic savants'are \\ individuals with autism who have \\ extraordinary skills. Brain mechanisms \\ underlying such capacities are still \\ unknown.
}

Aims To map the exceptional calendar capacity of a man with primary autism.

Method Positronemission tomography was used to map brain activity in a man who is able to associate a day of the week with the corresponding calendar date.

Results During the calendar task, the left hippocampus, the left frontal cortex and the left middle temporal lobe were activated.

Conclusions The cerebral circuit involved in this man's prodigious calendar skill is similar to that normally involved in memory retrieval tasks. These results suggest that the prodigious capacities may be sustained by memory processing.

Declaration of interest None. Funding detailed in Acknowledgements.
The term 'savant syndrome' refers to individuals who display an exceptional mental ability despite a low level of general cognitive ability (Treffert, 1988). These 'savant' capacities are more frequently observed in persons with autism, 'autistic savants', than in the non-autistic population (Rimland \& Fein, 1988). Such exceptional abilities include musical skills, mental calculation, outstanding mnemonic skills and extraordinary drawing abilities (Hermelin, 2001).

One of the most common savant abilities observed in people with autism is the socalled calendar calculation or calendar memory (Horwitz et al, 1969; O'Connor \& Hermelin, 1984; Kehrer, 1992; Kelly et al, 1997). This refers to the ability to generate the weekday of a given date within seconds, the spans varying from a few years to some centuries. Several cognitive hypotheses were formulated to account for this prodigious ability, such as eidetic imagery, high-speed calculation, raw memorisation and use of certain calendrical rules. However, calendar calculation seems to be sustained by memory but the neural mechanisms underlying this capacity are poorly understood.

To investigate the neural network implicated in prodigious calendar ability, we performed a positron emission tomography (PET) activation study in a 22-yearold savant with prodigious calendar capacities. Despite severe behavioural and cognitive impairment, he was able to generate, in a few seconds, a weekday corresponding to a date. He had been able to perform this association for the previous 18 years (since he was 4 years old) but was unable to perform this for future dates. Therefore we hypothesised that his prodigious calendar abilities were sustained by memory processing.

\section{METHOD}

\section{Case report}

We report functional brain mapping of a right-handed male who was 22 years old at the time of study. Signs of autism, such as social withdrawal, echolalia, stereotypic and repetitive motor mannerisms, persistent preoccupation with parts of objects, and self-harm were detected during the second year of life. Normal schooling was unsuccessful. At the age of 4 years he was admitted to a day-care psychiatric unit. He was also examined by a neuropaediatrician. The diagnosis of autism was made by a psychiatrist and a psychologist according to DSM-IV criteria (American Psychiatric Association, 1994). Diagnosis was confirmed by the Autism Diagnostic Interview - Revised (ADI-R) (Lord et al, 1994) (social interaction scores: 29; verbal communication scores: 24; non-verbal communication scores: 12; stereotypy scores: 9; age-onset criteria: 3 ). At the age of 20 years his global IQ was 66 (Wechsler Adult Intelligence Scale-Revised; Wechsler, 1981), with a score of 45 for performance and 83 for verbal abilities. He had typical autistic speech abnormalities (verbal perseveration, stereotypy, echolalia, abnormal prosody, neologism). Meticulous clinical evaluation was also performed. He had no infectious, metabolic, neurological or genetic diseases. $\mathrm{He}$ is not dysmorphic. Electroencephalography and magnetic resonance imaging (MRI) were normal.

An ethics committee approved this study and examination was performed with the informed written consent of the parents.

\section{Brain imaging protocol}

Positron emission tomography (PET) uses positron-emitting labelled carriers to produce an image of brain activity. One of the applications of PET is the study of functional brain activity by measuring regional cerebral blood flow during the performance of cognitive tasks. Regional changes in cerebral blood flow between two tasks reflect the mobilisation of functional units specific to the new task. Hence it is possible to identify the brain regions activated by the stimulus. The purpose of this study was to identify the regions activated by performance of the calendar task. To do this, blood flow images were obtained at baseline and during performance of the task and the two images were subtracted. Those regions that had been activated showed a change in blood flow.

\section{Task}

In the calendar task dates were chosen randomly over a period of 16 years (1982-1998). During the scan, dates were 
given orally by the investigator and the young man was asked to answer orally the day of the week that corresponded to the date (e.g. 26 February 1982 - Friday). Fifteen dates were given during $100 \mathrm{~s}$ of PET acquisition (1 question/answer every $6 \mathrm{~s})$.

In the word repetition control task a list of French objects was selected (e.g. car, house, toys). The investigator gave orally the name of an object and the young man was asked to repeat it orally (50 words during the $100 \mathrm{~s}$ of PET acquisition) in order to control for auditory perception and word production.

\section{Image acquisition}

Scanning was performed using an ECAT Exact HR+962 PET camera (Siemens, Knoxville, Tennessee, USA). Attenuationcorrected data were reconstructed into 63 slices, with a resulting resolution of $5 \mathrm{~mm}$ full width at half maximum. Relative cerebral blood flow was determined from the distribution of radioactivity after bolus intravenous injections of $\mathrm{H}_{2}{ }^{15} \mathrm{O}$ (Fox et al, 1984). Twenty seconds before each scan, $10 \mathrm{mCi}$ of $\mathrm{H}_{2}{ }^{15} \mathrm{O}$ was administered by an intravenous bolus injection. Data were collected over $80 \mathrm{~s}$. The young man was lying in the scanner in a quiet darkened room. Three measurements of relative cerebral blood flow were performed: (1) at rest; (2) during the auditory calendar task; and (3) during a control repetition of words. Tasks started $20 \mathrm{~s}$ before image acquisition. Three-dimensional T1 high-resolution MRI of the brain (General Electric 1.5-T Signa system, GE Medical Systems, Milwaukee, Wisconsin, USA) was also performed on the same day.

\section{Image analysis}

Statistical parametric mapping software (SPM96, Wellcome Department of Cognitive Neurology, London) was used for image realignment, transformation into standard stereotactic space (Talairach \& Tournoux, 1988), smoothing (15 mm Gaussian kernel) and statistical analysis (Friston et al, 1995). State-dependent differences in global flow were corrected using proportional scaling. To assess the individual pattern of activation we designed a multistudy model matrix. Images of five normal controls during rest were included in the model, allowing an estimation of inter-participant variability.
The three conditions (rest, calendar task and word repetition) were compared using the $t$-statistic subsequently transformed into a normally distributed $Z$ statistic. Z-maps were thresholded at 3.09 $(P<0.001)$.

\section{RESULTS}

During the calendar task 15 dates were given and the young man gave $100 \%$ correct responses. The calendar task induced a significant activation of a large left fronto-temporal network compared with rest. This network included: the left inferior (Brodmann area (BA) 45, 46, 47), middle $(\mathrm{BA}, 9,10)$ and precentral frontal cortex (BA 6), the left anterior cingulum, the left superior and middle temporal areas (BA 39, 21, 22) and the left hippocampus (Z-score $>3.09, P<0.001$ ).

The word repetition task induced activation of the left frontal (BA 6, 9, 10, 44), left temporal (BA 21, 22, 39) and right precentral and postcentral frontal cortex (BA 6, 4 and 43) ( $Z$-score $>3.09, P<0.001)$ compared with rest. There was no activation in the left hippocampus during the word repetition task.

Specific calendar task activation (calendar task compared with word repetition task, Fig. 1) was associated with significant activation $(Z$-score $>3.09, P<0.001)$ of the left hippocampus, of the left middle temporal gyrus (BA 21) and of the left inferior frontal gyrus (BA 47, 45).

\section{DISCUSSION}

Functional brain imaging offers a new means of investigating the cerebral networks involved in the exceptional abilities frequently displayed by those with autism. Prodigious calculation ability in a nonautistic individual has been linked to highly efficient memory processing sustained by prefrontal and medial temporal areas (Pesenti et al, 2001).

We performed a PET activation study to identify a brain network implicated in the prodigious calendar aptitude in people with autism. The present results show that the young man's capacity to associate a day of the week with a corresponding date of the calendar was associated with significant activation of a left fronto-temporal network, including the hippocampus, which is strongly implicated in memory processing (Cipolotti et al, 2001; Nadel \& Moscovitch, 2001). This hippocampal activation is in agreement with the clinical hypothesis that the young man's prodigious calendar capacity was sustained by memory processing.

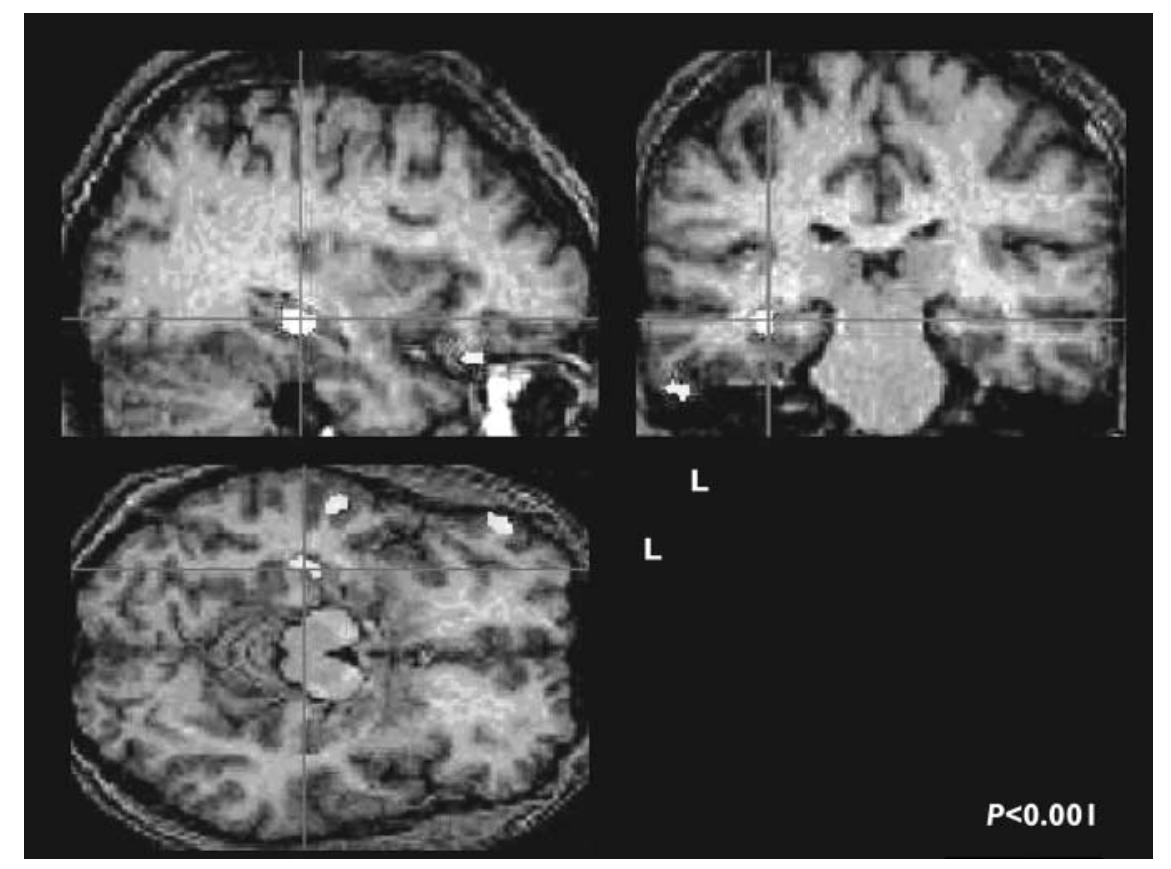

Fig. I Cortical activation of a savant during a calendar task. The calendar task was associated with a left (L) significant hippocampo-fronto-temporal activation compared with a control word repetition task. These results are represented in the sagittal, coronal and axial plane of the TI magnetic resonance imaging (Z-score $>3.09, P<0.001)$. 
However, the present findings must be considered in the light of some methodological limitations. First, as the calendar day-date association task is unusual, we have not compared the pattern of brain activation with that of normal controls. A study with a large number of individuals with the same savant capacities and an appropriate control group would help to establish a more general mechanism for this capacity in autism.

Second, the choice of a control task for the calendar condition was complex. The word repetition task controls for some aspects of speech perception and production but not for all cognitive components of the calendar task. This choice could limit the interpretation of the pattern of activation observed during the calendar task. However, the hippocampal activation was observed when comparing the calendar task with both control and rest conditions, and was not detected during the word repetition task. This implicates the hippocampus in the present calendar task. However, we cannot generalise the findings in this single individual to savant abilities in populations.

Despite these methodological limitations, this preliminary study disclosed a cerebral circuit involved in the prodigious calendar capacity of a savant. The pattern of activation observed during the calendar task implicated a selective brain network including the left inferior frontal cortex, the middle temporal cortex and the hippocampus. This network is normally activated during delayed memory retrieval processing in normal controls (Dupont et al, 2001). Therefore, the present results suggest that the prodigious calendar capacity of this young man may be sustained by a special memory processing.

These findings may lead to speculation that during development people with autism can 'overdevelop' a normal brain circuit and develop prodigious capacity, despite their severe cognitive and behavioural handicaps. The prodigious calendar capacity in autism and its associated brain network should be regarded in the light of an early developmental disorder. Autism might be associated with a developmental disorganisation of the neural circuits, facilitating the emergence of these peculiar networks.

Finally, our study illustrates how functional brain imaging offers a new perspective for the investigation of brain mechanisms underlying the still mysterious autistic savant syndrome.

\section{CLINICAL IMPLICATIONS}

- The capacity to associate a day of the week with a corresponding date is associated in this individual with significant activation of a fronto-temporal network including the hippocampus, which is highly implicated in memory processing.

- Functional brain imaging opens a new perspective for investigating the cerebral networks involving exceptional capacities in autism.

- The present results may lead to the speculation that during development people with autism can 'overdevelop' a normal brain circuit, giving rise to prodigious capacity, despite their severe cognitive and behavioural handicaps.

\section{LIMITATIONS}

- A single case study is inadequate for establishing a general mechanism for this capacity in autism.

- We cannot generalise the findings from a single individual to savant abilities in populations with autism.

Owing to the unusual nature of the calendar task, we did not ask our control group to participate in it, and so we could not compare the pattern of brain activation that it produced in a savant and in controls.

NATHALIE BODDAERT, MD, ERM 0205 INSERM-CEA, Service Hospitalier Frédéric Joliot, Orsay, and Service de Radiologie Pédiatrique, Hôpital Necker Enfants Malades, Paris; CATHERINE BARTHÉLÉMY, MD, PhD, INSERM Unité 316, CHU Bretonneau, Tours; JEAN-BAPTISTE POLINE, PhD, ERM 0205 INSERM-CEA, Service Hospitalier Frédéric Joliot, Orsay; YVES SAMSON, MD, Service des Urgences Cerebro-Vasculaires, Groupe Hospitalier Pitié-Salpêtrière, Paris; FRANCIS BRUNELLE, MD, ERM 0205 INSERM-CEA, Service Hospitalier Frédéric Joliot, Orsay, and Service de Radiologie Pédiatrique, Hôpital Necker Enfants Malades, Paris; MÔNICA ZILBOVICIUS, MD, PhD, ERM 0205 INSERM-CEA, Service Hospitalier Frédéric Joliot, Orsay, France

Correspondence: Dr Mônica Zilbovicius, Service Hospitalier Frédéric Joliot, DRM, DSV, CEA, 4 Place du General Leclerc 91406, Orsay, France. Tel: +33 (I)0I 698678 90; fax: +33 (I)0I 698677 28; e-mail: zilbo@shfj.cea.fr

(First received 17 February 2004, final revision 19 October 2004, accepted 2I October 2004)

\section{ACKNOWLEDGEMENTS}

We thank the young man and his parents for their participation in this study. The study was supported by the Programme Hospitalier de Recherche Clinique - Ministère de la Santé (France), Fondation France - Télecom and Fondation de France.

\section{REFERENCES}

American Psychiatric Association (1994) Diagnostic and Statistical Manual of Mental Disorders (4th edn) (DSM-IV). Washington, DC: APA.

Cipolotti, L., Shallice, T., Chan, D., et al (200I) Long term retrograde amnesia... the crucial role of the hippocampus. Neuropsychologia, 39, 151-172.

Dupont, S., Samson, Y., Van de Moortele, P. F., et al (2001) Delayed verbal memory retrieval: a functional
MRI study in epileptic patients with structural lesions of the left medial temporal lobe. Neuroimage, 14, 995-1003.

Fox, P. T., Mintun, M. A., Raichle, M. E., et al (1984) A noninvasive approach to quantitative functional brain mapping with $\mathrm{H}_{2}{ }^{15} \mathrm{O}$ and positron emission tomography Journal of Cerebral Blood Flow and Metabolism, 4, 329333.

Friston, K., Holmes, A. P., Worsley, K. J., et al (1995) Statistical parametric mapping in functional imaging: a general linear approach. Human Brain Mapping, 2, 189-210.

Hermelin, B. (200I) Bright Splinters of the Mind. A Personal Story of Research with Autistic Savants. London: Jessica Kingsley.

Horwitz, W. A., Deming, W. E. \& Winter, R. F. (1969) A further account of the idiots savants, experts with the calendar. American Journal of Psychiatry, 126, 4I2-415.

Kehrer, H. E. (1992) Savant capabilities of autistic persons. Acta Paedopschiatrica, 55, I5I-I55. 
Kelly, S. J., Macaruso, P. \& Sokol, S. M. (1997) Menta calculation in an autistic savant: a case study. Journal of Clinical and Experimental Neuropsychology, 19, 172-184.

Lord, C., Rutter, M. \& Le Couteur, A. (1994) Autism Diagnostic Interview - Revised: a revised version of a diagnostic interview for caregivers of individuals with possible pervasive developmental disorders. Journal of Autism and Developmental Disorder, 24, 659-685.

Nadel, L. \& Moscovitch, M. (200I) The hippocampal complex and long-term memory revisited. Trends in Cognitive Sciences, 5, 228-230.
O'Connor, N. \& Hermelin, B. (1984) Idiot savant calendrical calculators: maths or memory? Psychological Medicine, 14, 801-806.

Pesenti, M., Zago, L., Crivello, F., et al (200I) Menta calculation in a prodigy is sustained by right prefrontal and medial temporal areas. Nature Neurosciences, $\mathbf{4}$ 103-107.

Rimland, B. \& Fein, D. (1988) Special talents of autistic savant in the exceptional brain. In The Exceptional Brain (eds L. K. Obler \& D. Fein), pp. 474-492. New York: Guilford Press.
Talairach, J. \& Tournoux, P. (1988) Co-Planar Stereotaxis Atlas of the Human Brain. New York: Thieme Medical Publishers.

Treffert, D. A. (1988) The idiot savant: a review of the syndrome. American Journal of Psychiatry, 145, 563-572.

Wechsler, D. (198I) Wechsler Adult Intelligence Scale Revised (WAIS - R) Manual. Cleveland, $\mathrm{OH}$ :

Psychological Corporation. 